\title{
"A GENTE SEMPRE TEM UMA CONVICÇÃO MUITO MAIOR DO QUE VAI FAZER AOS 20 DO QUE COM 15 ANOS": A JUVENTUDE COMO "IMATURIDADE"
}

\author{
Dranda Alessandra Amaral da Silveira \\ Dra Caroline Braga Michel \\ Universidade Federal de Pelotas
}

\begin{abstract}
RESUMO: Essa pesquisa tem como objetivo analisar o que os sujeitos que não possuem modificações corporais dizem sobre elas, relacionando-as com o debate sobre a juventude. Consideramos práticas corporais, para essa pesquisa, as vinculadas ao body modification, que são: os piercings, as tatuagens, os dilatadores, as escarificações etc. Para tanto, utilizamos como metodologia de pesquisa o Grupo Focal. Esse estudo foi realizado numa escola de ensino médio, intitulada Instituto Federal de Educação, Ciência e Tecnologia do Rio Grande do Sul (IFRS). As principais considerações
\end{abstract}

encontradas durante a análise dos dados foram: a preocupação em associar às práticas corporais a algum significado; os participantes reforçaram o discurso de que a juventude não possui "maturidade suficiente" para tomar decisões importantes, devido a inconstância de sentimentos que é associado ao ser jovem; também identificamos a preocupação com o emprego, já que os jovens da pesquisa demarcam que possuir uma modificação corporal pode comprometer o acesso ao mercado do trabalho.

PALAVRAS-CHAVE: corpo; juventude; body modification.

\section{WE ALWAYS HAVE A MUCH CONVICTION TO 20 YEARS OF AGE THAN TO 15: WHAT THE YOUNG PEOPLE SAY ABOUT THE PRACTICE OF BODY MODIFICATIONS}

\begin{abstract}
This study aims to examine the young people that have no physical modifications are saying about them, relating them to the debate on youth. We consider body practices for this survey, those related to body modification, which are: piercings, tattoos, dilators, the scarification etc. We used as a research methodology the focus group. This study took a high school, entitled Federal Institute of Education, Science and Technology of Rio Grande do Sul (IFRS). The main
\end{abstract}

considerations encountered during data analysis were: concern for the bodily practices associated with some meaning; participants reinforced the argument that youth does not have "mature enough" to make important decisions because of inconstancy of feeling that is associated with being young, we also identified a concern with employment, as the young research demarcate to possess a body modification can compromise access to the labor market.

KEYWORDS: body; youth; body modification. 


\section{Educere "Educare \\ Revista de EduCAČ̃̃o}

Programa de Pós-Graduação em Educação - Universidade Estadual do Oeste do Paraná

\section{INTRODUÇÃO}

A temática da corporeidade tem sido abordada sobre diferentes focos, proliferando inúmeros discursos referentes ao modo de ser e estar corporalmente no mundo. Santin (1992) afirma que corporeidade é um conceito abstrato que indica estudos sobre corpos de acordo com as diferentes compreensões desenvolvidas culturalmente ao longo da história. Atualmente, podemos caracterizar o corpo como um espaço marcado pelas modificações, uma vez que a elas é atribuída a noção de aperfeiçoamento, pois o corpo, na sua essência e no seu desenvolvimento considerado "natural", é considerado imperfeito (SIBILIA, 2009).

Esse desejo de modificar a corporeidade tem sido bastante evidenciado entre os jovens. Eles são interpelados por esse discurso e buscam alinhar-se ao modelo de corpo perfeito e ideal apontado e incentivado pela sociedade. O desejo de adequar-se a um padrão social que está associado à valorização da juventude. "Deseja-se chegar a ela cedo e nela permanecer por muito tempo" (SILVA e SOARES, 2003 p. 86). As palavras dessas autoras corroboram com a análise sobre a supervalorização que a sociedade contemporânea apresenta com relação à juventude. Nesse sentido, Ariès (1986) complementa que estar jovem e bonito é um ideal da nossa sociedade.

A partir das temáticas ligadas à corporeidade, percebemos que, na atualidade, existem muitos artificios usados pelos indivíduos para construir o seu jeito de ser dentre eles, as modificações corporais. É através de determinadas marcas (biológicas ou adquiridasi) que os sujeitos se constituem e são posicionados na sociedade, isso se dá pela sobreposição de determinadas marcas sobre outras, que acabam ditando os padrões que estão dentro de uma determinada norma.

As maneiras mais conhecidas e aceitas na nossa sociedade de modificações corporais são a musculação/ginástica, o bronzeamento artificial, 


\section{Educere "Educare \\ Revista de EduCAČ̃̃o}

Programa de Pós-Graduação em Educação - Universidade Estadual do Oeste do Paraná

as dietas, as cirurgias plásticas etc. Além dessas, há pessoas que visam se construir através de outras técnicas como, por exemplo, as praticadas pelos adeptos do grupo denominado body modification. Esse termo remete às modificações corporais realizadas voluntariamente e caracterizadas, principalmente, pelo seu caráter de irreversibilidade. Dentro desse grupo, as práticas mais conhecidas e usadas são os piercings, as tatuagens, as escarificações e os dilatadores.

Diante de tantas possibilidades em se produzir o sujeito, tivemos interesse em problematizar as questões vinculadas aos discursos dos jovens sobre a temática da corporeidade, os quais interpelam e de certa maneira os constituem como sujeitos numa sociedade contemporânea ocidental. Sendo assim, neste artigo temos como objetivo identificar o que os jovens sem modificação corporalii dizem a respeito das práticas do body modification. Para delimitar o campo de análise, a pesquisa foi realizada com jovens, com idades entre 14 e 17 anos, de uma escola denominada IFRS (Instituto Federal do Rio Grande) de ensino médio, localizada na cidade de Rio Grande/RS. Essa escola foi escolhida por sabermos de antemão da existência de alunos com modificações corporais e também por ter sido a única instituição, dentre as consultadas, que permitiu a realização da investigação. As demais não demonstraram interesse, tampouco disponibilizaram o espaço para a pesquisa por consideraram que ao debater sobre o assunto estariamos incentivando os alunos a fazerem modificações corporais. A pesquisa foi realizada por meio do Grupo Focaliii por acreditarmos que com a utilização dessa estratégia metodológica é possivel perceber o que os participantes pensam e quais os seus posicionamentos sobre a temática através das discussões realizadas em pequenos grupos.

As questões referentes às técnicas do body modification foram problematizadas em dois grupos distintos - os que possuem modificação corporal e os que não possuem -, pelo fato de acreditarmos que as pessoas se constituem enquanto sujeitos através da aceitação ou não de determinadas 


\section{Educere "Educare \\ Revista de EduCAČ̃̃o}

Programa de Pós-Graduação em Educação - Universidade Estadual do Oeste do Paraná

práticas, nesse caso, o do uso ou não dessas modificações corporais. No entanto, neste artigo analisaremos somente os dados coletados do grupo que não possui modificação corporaliv.

E por que focar nos jovens/juventude? Por suspeitarmos que os discursos ligados ao body modification estejam dirigidos, principalmente, para esse grupo e nesse sentido há jovens que se apropriam desse discurso e outros que não, e assim, vão constituindo suas juventudes. A escolha por esse grupo de indivíduos, em especial, também foi feita porque percebermos que mesmo com o crescente interesse pelo uso das modificações corporais, esses sujeitos não se tornaram adeptos. Não aderiram às modificações corporais, recorrendo ao uso dos piercings, das tatuagens, das escarificações e dos dilatadores, existem sujeitos que escapam a esse discurso e não tem interesse em aderir ao uso desses adornos corporais. No entanto, esses indivíduos constituem sua juventude e sua corporeidade de outras maneiras. Assim, torna-se fundamental que possamos compreendê-las e discuti-las.

Para situar o leitor, destaca-se que a organização desse artigo se deu em três partes. Na primeira apresentamos os caminhos metodológicos utilizados para a coleta dos dados. Na segunda parte definimos o que são as modificações corporais e as práticas realizadas no movimento body modification e, ainda, analisamos o que tem sido pensado sobre as questões referentes à juventude, demarcando o que esse termo significa na pesquisa. Por fim, na terceira parte discutimos os dados coletados no Grupo Focal.

\section{CAMINHOS DA PESQUISA}

A metodologia escolhida para coleta dos dados dessa pesquisa foi a do Grupo Focal. Essa técnica se mostrou bastante apropriada para verificarmos o que os jovens que não possuem modificação corporal dizem sobre elas, pois ela se caracteriza pelo debate aberto entre os participantes sobre uma temática específica. Mostrou-se bastante eficaz, pois não visa julgar as falas e as 


\section{Educere "Educare \\ Revista de EduCAČ̃̃o}

Programa de Pós-Graduação em Educação - Universidade Estadual do Oeste do Paraná

condutas dos jovens, ou seja, não queremos avaliar se as respostas são certas ou erradas e nem quantificá-las, e sim saber o que os sujeitos da pesquisa pensam sobre a temática apresentada. O Grupo Focal é um tipo de conversa realizada com grupos pequenos e homogêneos de pessoas (MINAYO, 2006), no sentido de que os sujeitos escolhidos para participar da discussão devam apresentar, no mínimo, um ponto em comum entre si e com o tema da pesquisa.

Especificamente com relação a esta investigação, o grupo foi constituído com alunos de uma escola de ensino médio e técnico, denominada Instituto Federal do Rio Grande do Sul (IFRS), situada na cidade de Rio Grande/RS, localizada na região central da cidade. Essa escola apresenta um processo de aprendizagem direcionado para a formação profissional, tendo como principal característica a formação para o mercado de trabalho. Outro destaque é que para iniciar a discussão o moderador elaborou uma apresentação com as imagens das práticas do body modification, pois esse momento auxilia para começar a discussão.

Para esse artigo, como já mencionado, nos deteremos no Grupo Focal que foi realizado com os jovens que não possuíam modificação corporal, ou ainda, que não consideravam possuir modificações. Assim, participaram do encontrov 13 jovens, sete meninos e seis meninas, com idades entre quinze e dezesseis anos, estudantes dos $1^{\circ}, 3^{\circ}$ e $4^{\circ}$ anos do Ensino Médio. Mesmo sabendo que uma das recomendações do Grupo Focal é a constituição de grupos pequenos, em função do significativo interesse dos jovens em fazer parte da discussão, não nos sentimos a vontade para excluir os interessados, já que eles fizeram questão de participar do encontrovi.

\section{3. "TER 18 ANOS PARA PODER FAZER UMA MODIFICAÇÃO CORPORAL, NÃO QUER DIZER NADA, O QUE IMPORTA É A CABEÇA" (Brenda) vii}

$\mathrm{Na}$ atualidade vem crescendo, ao mesmo tempo, dois discursos referentes ao corpo. Um busca enaltecer o corpo natural e para isso investe em ginásticas, 


\section{Educere Educare \\ ReVISTA DE EduCACÃ̃o}

Programa de Pós-Graduação em Educação - Universidade Estadual do Oeste do Paraná

alimentações denominadas naturais, valorizando o que é orgânico. Outro discurso considera o corpo natural defeituoso, que, por isso, precisa ser modificado. Le Breton (2003) chama atenção que, na contemporaneidade, o corpo original/natural é considerado como imperfeito. De certa maneira ambos possuem o mesmo pressuposto, ou seja, que existe uma essência de corpo e que essa deve ser recuperada ou alterada.

Mesmo tendo conhecimento dessas duas visões, nos focaremos no que pode ser considerado como o desejo de criação do corpo, essa vontade que vem sendo sistematicamente estimulada. Segundo Le Breton (2003), o corpo é uma matéria prima a modelar, que está em constante construção para se encaixar no design do momento em que está vivendo. Para o autor, a sociedade ocidental cultua os corpos modificados e, a partir disso, investe na modificação dos mesmos.

Para conseguir o padrão de corpo adequado, as pessoas buscam diversas alternativas que são encontradas no mercado da aparência (SIBILIA, 2009). Nesse sentido, Le Breton afirma que:

[...] não é mais o caso de contentar-se com o corpo que se tem, mas de modificar suas bases para completá-lo ou torná-lo conforme à ideia que dele se faz. Sem o complemento introduzido pelo indivíduo em seu estilo de vida ou suas ações deliberadas de metamorfose fisicas, o corpo seria uma forma decepcionante, insuficiente para acolher suas aspirações (LE BRETON, 2003, p. 22).

Dentro desta perspectiva, existem cada vez mais pessoas interessadas em realizar algum tipo de modificação em seus corpos, sendo possível dividir essa vontade, para efeito desta análise, em dois subgrupos: no primeiro, estão os sujeitos que buscam se adequar a um modelo de beleza aceito, incentivado e valorizado pela nossa sociedade, investindo em procedimentos, tais como lipoaspiração, dietas, ingestão suplementos alimentares e outros. No segundo subgrupo estão os praticantes do body modification, que é caracterizado, por Pires (2005), como o uso de técnicas que possibilita ao indivíduo adquirir características não similares às inatas, aplicadas ao corpo por meio de 


\section{Educere "Educare \\ ReVISTA DE EduCACÃ̃o}

Programa de Pós-Graduação em Educação - Universidade Estadual do Oeste do Paraná

perfurações, cortes, queimaduras e cirurgias. Seus adeptos buscam a elaboração de um corpo com um estilo que não siga o tradicional, ou seja, aquele que rompe com a imagem convencional que se deve ter ou que é esperado que se tenha.

Várias técnicas caracterizam e constituem o body modification e são classificadas, por Urbin e Grassetti (2005), conforme suas formas de intervenção, como: a) as mais populares e conhecidas e b) as radicais e menos conhecidas. No primeiro grupo temos práticas como as tatuagens (fig. 1 e 2), que são aplicações subcutâneas realizadas através da introdução de pigmentos por meio de agulhas; os piercings (fig. 3 e 4), que se caracterizam por perfurações de diversas partes do corpo, com a intenção de introduzir peças de metal; as escarificações (fig. 5), que são feitas pela fabricação de cicatrizes, com intenções espirituais - como é comum em tribos africanas - ou para embelezamento; e os alargadores (fig. 6), que são pinos de aço inox, madeira ou pedra, que são usados para alargar o lóbulo da orelha ou de outras partes do corpo. Exemplos dessas práticas podem ser observadas nas figuras apresentadas a seguirviii:

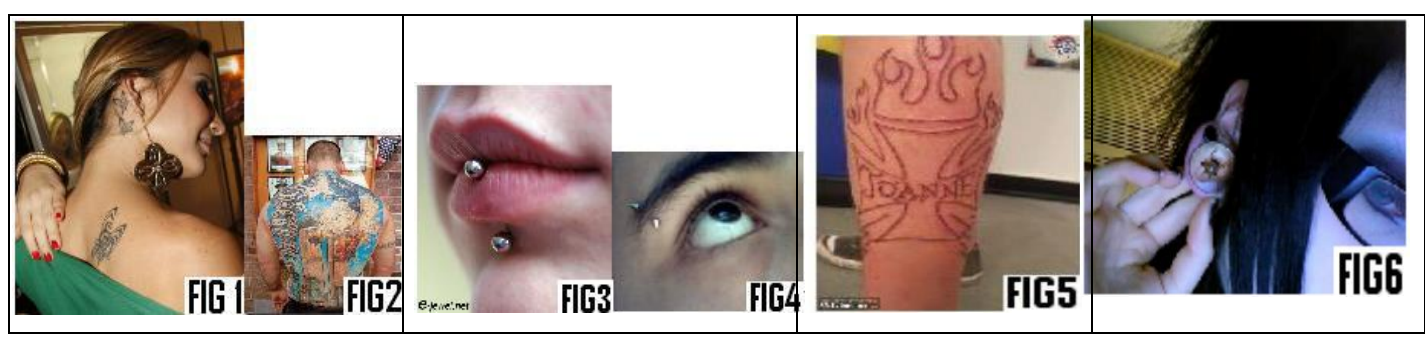

Fonte: banco de dados pesquisadoras (figuras retiradas do site google).

No segundo grupo, dentre as práticas mais radicais e menos conhecidas podemos citar o branding (fig. 7), que é a aplicação de metal aquecido na pele, deixando uma queimadura que eventualmente se transforma em uma cicatriz; o tong split (fig. 8)- bifurcação da língua - procedimento cirúrgico que divide parte da língua em duas metades, dando a aparência de uma língua de lagarto ou cobra, com o tempo, é possivel mexer as duas partes individualmente; o implante subcutâneo (fig. 9), que consiste em inserir objetos, que podem ser de vários materiais - silicone, plástico, osso, metal - e formatos, sob a pele, criando um 


\section{Educere Educare \\ RevisTA De EduCAC̄̃̃o}

Programa de Pós-Graduação em Educação - Universidade Estadual do Oeste do Paraná

relevo; pocketing (fig. 10), que é considerado uma anti-perfuração, em que parte do material utilizado fica sob a pele e outra - podendo uma barra ou uma fita fica exposta; e, por fim, a suspensão corporal (fig. 11), que consiste em pendurar uma pessoa com ganchos, inseridos como piercings temporários, e suspendê-los num período de 20 a 30 minutos, deixando-os pendurados pela pele. Para seus adeptos a suspensão não é considerada como uma modificação corporal, mas sim um esporte radical.

Tais práticas podem ser observadas nas imagens apresentadas a seguir:

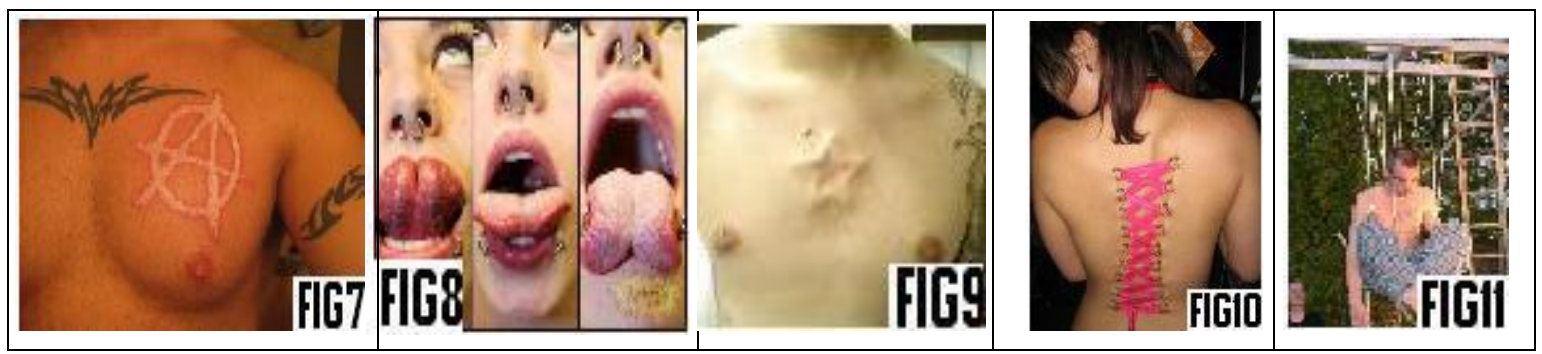

Fonte: banco de dados pesquisadoras (figuras retiradas do google)

Dentro das práticas do body modification, algumas são consideradas milenares, pois já são utilizadas há muitos séculosix, mas foram retomadas na contemporaneidade demarcando outro estilo de construir a própria corporeidade. Ou seja, as pessoas na contemporaneidade resgataram essas práticas e através delas se constituem enquanto sujeitos. Nesse sentido, para autores como Le Breton, as pessoas utilizam diversas técnicas para mudar seus corpos e, "[...] ao mudar o corpo, o indivíduo pretende mudar sua vida, modificar seu sentimento de identidade [...]" (LE BRETON, 2003, p. 30).

No que diz respeito aos jovens participantes da pesquisa, é interessante ressaltar que embora eles não possuíssem modificações corporais relacionadas ao body modification, a ideia de alterar o corpo era bastante recorrente no grupo, pois os estudantes se mostraram bastante familiarizados com as técnicas apresentadas, expressando entendimento inclusive sobre a maneira como elas 


\section{Educere Educare \\ ReVISTA DE EduCACÃ̃o}

Programa de Pós-Graduação em Educação - Universidade Estadual do Oeste do Paraná

são realizadas. Para eles, o ato de se modificar deve estar atrelado a um motivo, um significado. Sobre isso, os participantes fizeram os seguintes comentários:

"Para marcar um momento da vida, bah nasceu um filho!" (Derick);

"Ah sei lá, para diferenciar a pessoa, tipo personalizar a pessoa" (Thalison);

"Eu tenho um amigo tatuador e diz que normalmente as pessoas falam que vão se tatuar por causa de algum sentimento, que elas estão sentindo, geralmente felicidade ou revolta é sempre pelos sentimentos extremos" (Derick);

"Acho que um furo não significa muita coisa, mas uma tatuagem significa muito mais" (Samara);

"Geralmente é com motivos dentro quando tu estás conversando com a pessoa sobre tatuagem, ela vai te explicando os motivos por que fez, e diz ah ninguém tem igual a minha!" (Brenda).

$\mathrm{Na}$ busca por ser diferente, Ortega (2006, p. 53-54) salienta que o ato de fazer modificações corporais está relacionado ao caráter de "autenticidade" buscada pelos sujeitos, rompendo com o mercado da aparência do que é bonito, do que é considerado esteticamente perfeito e ideal pela sociedade. O autor coloca ainda que essas modificações não devem ser "consumidas como meros signos", pois deixam marcas permanentes. Esse desejo de ser único leva alguns sujeitos a recorrem ao uso das modificações corporais e este argumento apareceu na discussão, reforçando, assim, a intenção de ser diferente através da alteração do próprio corpo. Brenda, participante do grupo, enfatiza o uso da modificação com esse objetivo, quando traz o exemplo da realização da tatuagem: "A minha amiga diz: - eu fiz uma porque nunca vi em ninguém. A maioria das pessoas que fazem procuram não fazer igual a do outro" (Brenda).

Embora demonstrasse conhecimento e um certo fascínio por algumas práticas do body modification, os jovens valoraram e julgaram as práticas mais "radicais", como "equivocada" ou ainda como "algo inexplicável". Os participantes do Grupo Focal demonstraram uma certa rejeição à práticas como: implantes subcutâneos, bifurcação de língua, branding e a suspensão. Disseram que tais práticas são "exageradas". Sobre esse aspecto, surgiram os seguintes 


\section{Educere "Educare \\ ReVISTA DE EduCACÃ̃o}

Programa de Pós-Graduação em Educação - Universidade Estadual do Oeste do Paraná

comentários: "Colocar guampas que coisa feia" (Joana); "Ficar suspenso pela pele acho que não tem necessidade de fazer isso" (Kevin).

No decorrer da discussão também foi abordado sobre as práticas que eles consideram mais aceitas e incentivadas socialmente. Ortega (2006) as identifica como sendo as tatuagens e os piercings visiveis, por serem os mais comum na nossa cultura contemporânea, tornando-se mainstream ${ }^{x}$. No entanto, é possível incluir nessa classificação os dilatadores. O interesse por eles surgiu recentemente, mas vem sendo aceito socialmente. Suspeita-se que essa admissão de determinadas práticas e não de outras se dá pelo fato de algumas marcas já terem sido incorporadas e acolhidas pela sociedade (ORTEGA, 2006). Nesse sentido, surgiram as seguintes opiniões:

"Esteticamente ela (tatuagem) é mais bonita do que marcar a pele com ferro quente. O piercings também é bonito" (Kevin).

"A tatuagem feita no rosto é horrivel, mas se for feita aqui (pulso), ou aqui (perna), ou até em todas as costas como a do cara que foi mostrado na apresentação é bonita. Eu conheço um cara que tem baita Buda na barriga, e eu acho um exagero é como tu ter um dilatador que cabem três dedos eu acho outro exagero. Pode ter um pequeno ai é normal" (Derick).

A partir dessas falas, é possivel identificar que, vinculadas às práticas do body modification, já se constituiu uma hierarquização das marcas corporais (LOURO, 2004), ou seja, nessa lógica, percebermos que há marcas que "podem valer mais ou menos" (ib, p.75). A partir disso, podem ser definidas como dentro ou fora da norma.

são realizados investimentos - continuados, reiterativos, repetidos. Investimentos produzidos a partir de múltiplas instâncias sociais e culturais: posto em ação pelas famílias, pelas escolas, pelas igrejas, pelas leis, pela mídia ou pelos médicos, com o propósito de afirmar e reafirmar a norma [...] (LOURO, 2004, p. 82).

Nesse sentido, a norma visa produzir a normalidade e o normal, que, segundo Castro (2009, p. 310) é efeito "da valorização das condutas", de "uma conformidade que se deve alcançar; busca homogeneizar”. A partir dessa perspectiva, podemos observar que os sujeitos que participaram desta Revista Educere Et Educare, Vol. 13, N. 27, jan./abr. 2018. Ahead of Print. 


\section{Educere "Educare \\ Revista de EduCAČ̃̃o}

Programa de Pós-Graduação em Educação - Universidade Estadual do Oeste do Paraná

investigação são interpelados pelos discursos que estabelecem o que, em termos das técnicas do body modification, são aceitáveis e quais as modificações que podem ser feitas para continuar sendo consideradas normais para a sociedade.

Sendo assim, quando determinadas práticas do body modification são aceitas e ainda classificadas como normais, nos remetemos a uma problematização realizada por Foucault (2001) sobre a norma. Segundo o autor, a norma é instituída para ditar quais devem ser os comportamentos e as condutas dos sujeitos e, assim, as pessoas que vêm se constituindo dentro do que a norma estipula serão considerados normais.

Além de buscar qualificar e corrigir os sujeitos, a norma é uma "medida que se institui a partir de um princípio geral de comparabilidade" (EWALD, 1993 p. 111), ela é modelar, serve de referência. A norma investe na comparação entre os sujeitos para poder distingui-los. Os indivíduos que se adéquam a ela são vistos como normais e aqueles que se desviam da norma, podem ser tidos como anormais. A norma produz comportamento, colocando-se como referência.

Articulando com a temática do body modification, a norma vem ditando que os sujeitos jovens que aderem às práticas classificadas como populares são tidos como "normais", legitimando essa maneira de intervir sobre a corporeidade. Por outro lado, a norma aponta como atitude desviante as práticas tidas como radicais, negativando essa maneira de modificar os corpos. No entanto, "a norma é uma medida que opera sem exclusão, por inclusão, absorção, assimilação, mesmo daquilo que poderia pretender excedê-la" (EDWALD, 1993, p. 112).

No caso das práticas iniciais do body modification, como a tatuagem, os piercings e os dilatadores pequenos, pode-se dizer que elas são mais admissiveis que o branding, a suspensão, a bifurcação de língua, as quais causaram estranhamento para o grupo. Segundo Louro (2003, p. 01), isso ocorre pelo fato de que "no interior de uma cultura, há marcas que valem mais e marcas que valem menos. Possuir (ou não possuir) uma marca valorizada permite antecipar 


\section{Educere Educare \\ ReVISTA DE EduCACÃ̃o}

Programa de Pós-Graduação em Educação - Universidade Estadual do Oeste do Paraná

as possibilidades e os limites de um sujeito". É como enfatiza uma das participantes do grupo diante do espanto dos colegas a essas práticas: "é que a gente já está mais acostumado com o uso dos piercings, das tatuagens e dos dilatadores seria igual se todo mundo fizesse suspensão" (Brenda).

Por termos definido problematizar as compreensões acerca das modificações corporais de um grupo de jovens, acreditamos ser importante abordar o que estamos entendendo por juventude. Sendo assim, salientamos que nas palavras Coutinho e Portinari (2006, p.61) "ser jovem, na cultura ocidental contemporânea, é, sobretudo, uma forma de identidade, um estilo de vida”. Entendemos que essa perspectiva dos autores vai ao encontro com essa pesquisa, uma vez que busca problematizar esse termo de maneira ampla, levando em consideração as questões culturais, sem descartar outros fatores que demarcam o que é ser jovem, como por exemplo, a faixa etária, o desenvolvimento corporal etc.

Contribuindo para o entendimento sobre o conceito deste termo, Pais (1990, p. 149) propõe que olhemos a juventude de maneira ampla, sugerindo dois eixos:

Como aparente unidade (quando referida a uma fase de vida) e como diversidade (quando estão em jogo diferentes atributos sociais que fazem distinguir os jovens uns dos outros). De facto, quando falamos de jovens das classes médias ou de jovens operários, de jovens rurais ou urbanos, de jovens estudantes ou trabalhadores, de jovens solteiros ou casados, estamos a falar de juventudes em sentido completamente diferente do da juventude enquanto referida a uma fase de vida.

Partindo do eixo da diversidade, é possivel atribuir inúmeras maneiras de ser jovem, por isso, podemos abordar esse conceito na sua pluralidade, ou seja, entendo-a como juventudes. Sendo assim, ser jovem varia e implica em ostentar diferentes comportamentos, condutas, características, que podem alterar, dependendo do lugar, do período histórico, entre outros aspectos. 


\section{Educere "Educare \\ Revista de EduCAČ̃̃o}

Programa de Pós-Graduação em Educação - Universidade Estadual do Oeste do Paraná

Para a juventude, são oferecidas múltiplas opções para compor o seu jeito de ser, como, por exemplo, roupas coloridas ou pretas, maquiagens, chapéus, bolsas, cintos, pinturas, cabelos de todos os tamanhos e cores, piercings, tatuagens, dilatadores, escarificações, expressões e linguagem que identificam e demarcam o que é ser jovem em nossa sociedade. A partir da adesão ou não a essas marcas, podem ser criadas inúmeras maneiras de se constituir um sujeito que vivência a sua juventude.

Ainda, segundo Pais (1990), quando se refere à juventude, a partir do eixo unidade, podemos relacioná-la a uma determinada faixa etária, que é uma característica importante, já que não é qualquer sujeito que é considerado jovem. Não concordamos com alguns discursos referentes à demarcação das idades, pelo fato deles serem estanques, ou seja, fixam um começo e um fim para uma pretensa fase. Quando trabalhamos com uma compreensão voltada para as fases fixas acabamos desconsiderando as diferenças individuais e as diversidades culturais. Mas essa demarcação etária não pode ser desconsiderada, pois vêm definindo os indivíduos jovens, não de maneira categórica.

$\mathrm{Na}$ fala dos participantes do Grupo Focal junto com as questões atribuídas à faixa etária, percebemos a presença do discurso sobre maturidade, já que, para eles, intervir sobre o corpo exige uma pretensa maturidade, ou seja, para esses sujeitos precisa se ter consciência sobre os possiveis problemas que a intervenção sobre a corporeidade pode vir a trazer, e essa maturidade/consciência só se adquire com o tempo, com o aumento da idade. Nesse sentido um aluno aponta que: "A gente sempre tem uma convicção muito maior do que vai fazer aos 20 do que com 15 anos" (Natanael).

Além disso, os participantes associam a maturidade a duas perspectivas: a biológica e corporal; e a emocional ou relacionando-a a formação da personalidade. No que se refere à primeira, os participantes afirmaram: "tem que 


\section{Educere "Educare \\ Revista de EduCAČ̃̃o}

Programa de Pós-Graduação em Educação - Universidade Estadual do Oeste do Paraná

ter noção que tu vais envelhecer com aquela tatuagem" (Brenda); "tem que ter ideia de que o corpo vai crescer e que a tatuagem estica" (Natanael).

$\mathrm{Na}$ primeira fala percebemos que eles associam essas modificações à juventude, pois não é esperado que um sujeito velho tenha uma tatuagem. $\mathrm{Na}$ segunda, vinculada ainda a maturidade biológica, está presente a noção de desenvolvimento e envelhecimento do corpo, demarcando que o sujeito, ao fazer alguma modificação durante a juventude, corre o risco de que ela sofra alterações com as mudanças corporais decorrentes do envelhecimento.

Tomando a maturidade em um sentido emocional, atribuindo a ela a noção de responsabilidade e de constituição de uma personalidade em formação, foram enunciadas as seguintes falas:

"Mas a minha maturidade era a mesma, a maturidade que eu tinha para decidir que eu queria um piercing no umbigo que se depois eu tirar pode ficar uma cicatriz ou uma marca é a mesma maturidade que eu iria ter agora. E foi a mesma maturidade que eu tive para não colocar uma tatuagem, acho muito legal, mas não agora" (Joana).

"Mas Joana é diferente tu ter uma cicatriz, um buraco ou um desenho" (Brenda).

"Uma criança não tem discernimento, eu vou fazer essa tatuagem, que legal essa tatuagem, ela não vai pensar vou lá cortar a minha pele, ela vai ficar marcada. Ela não pensa na tatuagem pensa em tudo ao redor" (Derick).

Diante dessa relação entre as modificações corporais e o discurso da maturidade surge a preocupação com a perenidade das marcas do body modification. Para eles, muitas vezes, o jovem não apresenta maturidade suficiente para decidir o que é certo ou errado, por isso, durante a juventude, eles não se percebem capazes de tomar decisões vinculadas às modificações corporais.

Hersey e Blanchard (1986, p. 180) definem maturidade como "a capacidade e a disposição das pessoas em assumir a responsabilidade de dirigir seu próprio comportamento". É nesse sentido que a discussão se fundamentou, pois para alguns alunos um jovem não tem ainda responsabilidade sobre seus atos e, por isso, quando realizam determinadas ações estão sujeitos ao Revista Educere Et Educare, Vol. 13, N. 27, jan./abr. 2018. Ahead of Print. 


\section{Educere Educare \\ ReVISTA DE EduCACÃ̃o}

Programa de Pós-Graduação em Educação - Universidade Estadual do Oeste do Paraná

arrependimento. Isso no caso das modificações corporais não pode acontecer, pois quem as faz, fica com uma marca definitiva no corpo. Eles associaram o ato de realizá-las durante a juventude como um ato de imaturidade, pois neste período o corpo está em transformação e a modificação corporal realizada pode se alterar com o passar do tempo.

Após discutirmos algumas questões referentes à juventude, articuladas com as falas dos participantes, pretendemos aprofundar a análise dos discursos dos jovens sobre as modificações corporais, por considerar que, a partir dessas práticas e do que se fala sobre elas, os jovens também produzem suas subjetividades. É essa discussão que apresentamos na seção seguinte.

\section{4. "ISSO É UMA MUTILAÇÃO AO CORPO"}

Para iniciar a discussão foi mostrado aos participantes imagens das práticas realizadas pelos adeptos ao body modification. Como afirmado anteriormente, apesar de eles serem do grupo dos jovens que não possuíam modificações corporais, demonstraram conhecimentos sobre todas as técnicas apontadas nas fotos apresentadas.

Algumas questões foram ganhando força durante a discussão, uma delas foi sobre a aceitação do uso das tatuagens, dos piercings e dos dilatadores. Para os participantes do Grupo Focal essas modificações são bonitas, mas devem ser realizadas "sem exageros", caso contrário, são vistas como "mutilação", "sem necessidade".

"Um atentado contra o corpo. A hora que tu falou de implante sob a pele, ou aquela de ficar dependurado, ou de cortar a língua. Isso é uma mutilação ao corpo" (Derick).

A caracterização de uma transformação corporal como mutilação é problematizada por Ortega (2006, p.51), identificando que

[...] a mídia se apropria com freqüência do discurso médico de automutilação e o dissemina na sociedade, apresentando-o como um problema social emocionalmente provocativo que faz surgir, entre os 


\section{Educere "Educare \\ Revista de EduCAČ̃̃o}

Programa de Pós-Graduação em Educação - Universidade Estadual do Oeste do Paraná

leitores, um sentimento misto de medo, repugnância e horror diante das descrições sensacionalistas de práticas de modificação corporal.

É através da disseminação desses julgamentos que algumas verdades ${ }^{\mathrm{xi}}$ são criadas e ditam o que os sujeitos devem considerar como certas ou erradas. Nesse sentido é interessante relacionar o processo de produção de verdades, que surgem de diferentes instâncias (mídia, escola, família etc.) sobre o corpo e a constituição de como deve ser o sujeito jovem.

Uma questão bastante relevante que emergiu nas falas dos participantes desta investigação foi a da empregabilidade. Essa preocupação com o emprego foi uma questão que nos surpreendeu, pois em nenhum momento suspeitávamos de que o ato de não se modificar estaria relacionado a questão do emprego, do vir a ser um profissional. Essa preocupação foi ressaltada em várias falas dos sujeitos desse grupo:

"Geralmente as pessoas fazem tatuagem e nem pensam nas consequências disso, tem um amigo do meu padrasto que ele fez uma tatuagem na perna e quando fizeram concurso para brigada ele não passou porque ele tinha uma modificação que iria aparecer com a farda” (Miguel).

"Eu particularmente gosto muito de tatuagem no pé acho muito bonita, já enchi muito o saco para fazer e até me conformei, porque eu quero fazer concurso público e acho que não é o momento para fazer, depois que eu conseguir um trabalho, um emprego fixo, ai eu acho que é o momento certo para fazer, mas agora não" (Samara);

"Eu tenho vontade de fazer uma tatuagem, mas eu penso muito nisso de emprego nessa situação colocada pela sociedade no caso, por que eu vou fazer essa tatuagem agora se eu sei que vou sofrer um preconceito muito grande?" (Miguel);

"Eu queria fazer uma tatuagem, mas eu quero entrar para as forças armadas, lá não pode" (Marcos);

"Eu tenho vontade de fazer, mas sou que nem a Samara só vontade, vou fazer só quando estiver estabilidade, um emprego, passado num concurso, sei lá. Eu também não quero fazer num lugar muito exposto, o ideal é nas costas" (Natanael);

"É por isso que uma criança de 12 anos não pode fazer modificação corporal, por que ela não vai pensar na estabilidade dela" (Miguel); 


\section{Educere Educare \\ ReVISTA DE EduCACÃ̃o}

Programa de Pós-Graduação em Educação - Universidade Estadual do Oeste do Paraná

"Eu quero fazer também, mas não agora primeiro por que minha mãe e nem meu pai não iriam deixar, e também quero deixar para depois que eu arrumar um emprego" (Emilly).

Para completar, questionamos os participantes se tinham interesse de realizar uma modificação corporal relacionada ao body modification e a maioria disse que sim. Apenas dois meninos e uma menina responderam que não tinham pretensão em ter uma tatuagem ou piercing e que nunca haviam pensado no assunto. Mesmo havendo um número significativo de estratégias discursivas que associam o ser jovem à realização de uma modificação corporal relacionada ao body modification, existem alguns sujeitos que não são interpelados por este discurso e que se produzem jovens de outras maneiras e se vinculando a outros atributos.

\section{CONCLUSÕES}

Ao realizar o Grupo Focal com esses jovens percebemos que a maioria deles foram interpelados pelo discurso das modificações corporais e muitos deles manifestaram interesse em ter uma modificação. No entanto, alguns fatores, para esses sujeitos, são determinantes para não realizar as modificações corporais durante a juventude, entre elas está a preocupação com o emprego, o vir-a-ser profissional. A partir disso, percebemos que eles foram envolvidos por algumas verdades que estão associadas às práticas do body modification, entre elas está à ideia de que ao possuírem poderão ser preterido quando forem buscar um "bom emprego".

$\mathrm{O}$ ato de realizar as modificações corporais, especificamente as abordadas nesta pesquisa, para os participantes do grupo, está vinculado à questão da maturidade, o que, para eles, os jovens ainda não possuem. Além disso, devido à questão da empregabilidade, os participantes afirmaram que realizar uma dessas práticas durante a juventude pode acarretar problemas no 


\section{Educere "Educare \\ Revista de EduCAČ̃̃o}

Programa de Pós-Graduação em Educação - Universidade Estadual do Oeste do Paraná

futuro e como eles alegam que o jovem é imaturo não pensará nessas consequências.

Outro aspecto que emergiu na discussão é o que estabelece a necessidade de atribuir algum significado às modificações corporais desejadas. Ou seja, para os participantes do Grupo Focal não se deve fazer uma alteração corporal sem ter um motivo que demarque um acontecimento. Nesse sentido, Le Breton (2003, p. 39) aponta que o corpo com uma modificação "é memória de um acontecimento forte [...], da qual o indivíduo pretende conservar uma lembrança". No grupo, essa relação foi especialmente associada à tatuagem, especificamente pela irreversibilidade que caracteriza esta prática e, por isso, deve-se atribuir a ela algum tipo de significado e que tenha marcado a vida do sujeito, como por exemplo, uma homenagem a alguém.

Além disso, o uso dos piercings e dos dilatadores foi vinculado diretamente ao embelezamento e não à noção de ousadia ou de coragem. Por isso, podem ser colocados sem "pensar", pois se for necessário eles podem ser retirados. Outro aspecto abordado pelo grupo para justificar a adesão às práticas do body modification é sustentado no discurso de "ser diferente". Para eles, algumas pessoas sentem a necessidade de serem únicos na sociedade e investem nessas modificações para alcançar esse objetivo.

Diante das discussões levantadas durante o Grupo Focal, percebemos que os sujeitos que participaram dessa pesquisa, mesmo não aderindo às práticas do body modification, foram interpelados pelo discurso das modificações corporais e independente dos motivos que os levaram a não aderirem a esta prática, a maioria demonstrou interesse em realizá-las.

No entanto, os participantes desta investigação, alegaram que não pretendem fazer uma modificação corporal durante a juventude, pois esse é um momento definido pela imaturidade. Segundo eles, não se deve tomar decisões 


\section{Educere Educare \\ ReVISTA DE EduCACÃ̃o}

Programa de Pós-Graduação em Educação - Universidade Estadual do Oeste do Paraná

importantes na juventude, pois elas refletiriam no futuro, principalmente no que diz respeito à empregabilidade.

\section{REFERÊNCIAS BIBLIOGRÁFICAS}

ARIĖS, Philippe. História social da criança e da família. Rio de Janeiro: Ed Guanabara, 1986.

CASTRO, Edgardo. Vocabulário de Foucault. Tradução Ingrid Xavier. Belo Horizonte: Autêntica, 2009.

COUTINHO, Fernanda. PORTINARI Denise. A roupa faz o homem: a moda como questão. In: ALMEIDA, Maria Isabel Mendes e EUGÊNIO, Fernanda (Org.). Culturas Jovens - novos mapas do afeto. Rio de Janeiro: Jorge Zahar, 2006.

EWALD, François. Foucault A Norma e o Direito. Trad: António Cascais. Lisboa: Veiga, 1993.

FISCHER, Rosa. Verdades em suspenso: Foucault e os perigos a enfrentar. In: Caminhos investigativos II: outros modos de pensar e fazer pesquisa em educação. Rio de Janeiro: DP\&A. 2002.

FOUCAULT, Michel. Os Anormais: collège de France (1974-1975). São Paulo: Martins Fontes, coleção tópicos, 2001.

HERSEY, Paul.; BLANCHARD, Hambleton. Psicologia para administradores: a teoria e as técnicas da liderança situacional. Trad. Edwino A. Royer. São Paulo, Editora Pedagógica Ed: Universitária, 1986.

LE BRETON, David. Adeus ao Corpo. Antropologia e Sociedade. São Paulo: Papirus. 2003.

LOURO, Guacira. Corpos que escapam. In: Estudos Feministas. Brasília, n ${ }^{\circ} 4$ ago - dez, 2003.

Um corpo estranho ensaios sobre sexualidade e a teoria queer. Belo Horizonte: Ed Autêntica, 2004.

MINAYO, Maria de Souza. O desafio do conhecimento: pesquisa qualitativa em saúde. São Paulo: Hucidec, 2006. 


\section{Educere Educare \\ ReVISTA DE EduCAC̄̃̃o}

Programa de Pós-Graduação em Educação - Universidade Estadual do Oeste do Paraná

ORTEGA, Francisco. Das utopias sociais às utopias corporais: identidades somáticas e marcas corporais. In: ALMEIDA, Maria Isabel Mendes e EUGÊNIO, Fernanda (Org.). Culturas Jovens - novos mapas do afeto. Rio de Janeiro: Jorge Zahar, 2006.

PAIS, José Machado. A construção sociológica da juventude - alguns contributos. Análise Social, 105/106, 139-165. Lisboa/ Pt: 1990.

PIRES, Beatriz. O corpo como suporte da arte: piercing, implante, escarificação, tatuagem. São Paulo: Senac. 2005.

SANTIN, Silvino. Educação Física: temas pedagógicos. Porto Alegre: EST/ESEF, 1992.

SIBILIA, Paula. O corpo modelado como imagem: o sacrificio da carne pela pureza digital. In: RIBEIRO, Paula (org). Corpo, gênero e sexualidade: composição e desafios para a formação docente. Rio Grande: FURG, 2009.

SILVA, Rosimeri e SOARES, Rosãngela. Juventude, Escola e Mídia. In: FELIPE, Jane; GOELlNER, Silvana e LOURO, Guacira (Org.) Corpo, Gênero e Sexualidade um debate contemporâneo na educação. Petrópolis, Ed vozes, 2003.

URBIM, G. \& GRASSETTI, B. Navalhas na Carne. In: Revista Superinteressante. São Paulo: abr -mai, 2005, p. 68-71.

\footnotetext{
i Conforme LOURO (2004), as marcas biológicas podem ser as de gênero, de sexo, de etnia, de nacionalidade etc. Já as adquiridas podem ser uma aliança, corpo malhado, um piercing etc.

ii Para essa discussão serão considerados sem modificação corporal aqueles sujeitos que não aderiram às práticas conhecidas como tatuagens, piercings, escarificações, dilatadores etc. Nesse artigo, pretendemos aprofundar as práticas referentes ao body modification, conceito esse que será melhor explicado no tópico sobre modificação corporal. Entendemos que há diferenças entre as expressões body modification e modificação corporal, mas para efeito deste texto, estamos usando-as com sinônimo.

iii Utilizamos como referencial desta metodologia os estudos de Pichon-Rivièri (1998), Gatti (2005) e de Minayo (2006).

iv Os dados que emergiram com os alunos que possuíam modificações corporais foi publicado na Revista Textura - ULBRA, v.18, n. 37, 2016 com o título Discutindo as práticas do Body Modification e as possiveis produções das identidades jovens.

v Realizamos um encontro com este grupo de jovens com duração de $4 \mathrm{hs}$, o qual foi filmado e transcrita com a intenção de buscar as recorrências nas falas dos jovens, as questões que mais emergiram durante a conversa.

vi Vale salientar que Nesse encontro do Grupo Focal, tínhamos a intenção de realizar a discussão apenas com os jovens que não possuíam nenhuma das práticas associadas ao body modification. No entanto, uma aluna do $3^{\circ}$ ano da IFRS, com piercing no umbigo, escolheu fazer parte desse grupo, pois ela não se considerava modificada.
} 


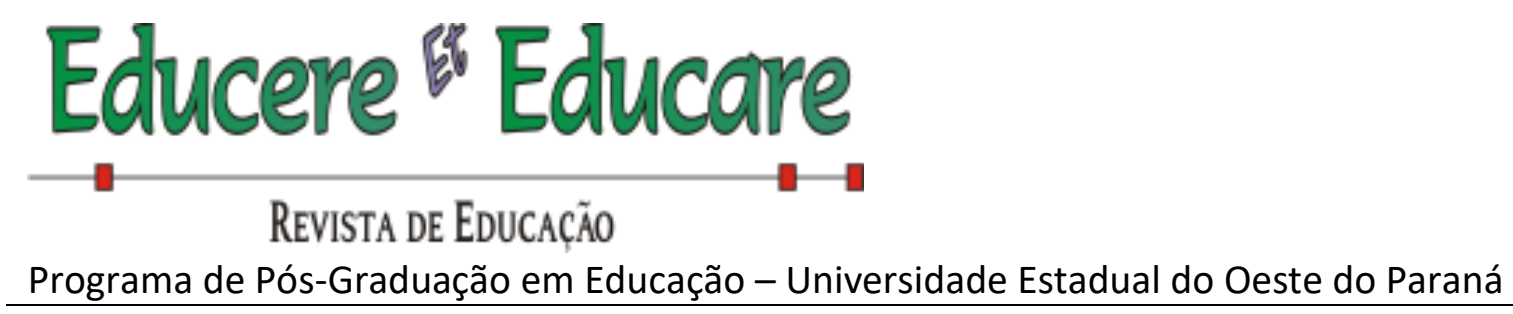

vii A partir desse momento do texto todas as frases que estão em itálico, com espaçamento simples e entre aspas são as falas dos participantes do grupo. Os nomes são fictícios e foram trocados para preservar a identidade dos alunos.

viii Todas as imagens que ilustram as práticas do body modification, foram retidas da apresentação mostrada durante a realização do Grupo Focal.

ix Registros sobre mumificação apontam que as primeiras ocorrências de práticas de modificação corporal datam de entre 4000 e 2000 a.C. no Antigo Egito, mais especificamente a tatuagem.

x Não possui uma única palavra para traduzi-la, mas pode se entender nesse contexto como a integração a aceitação de alguma coisa ou de alguém ao grupo dominante. Nesse caso se refere a aceitação das práticas iniciais do body modification.

xi Verdade sendo aquilo que nos é dado como salvação, ideal, padrão, sem serem questionadas, pois simplesmente aceitamos o que ela impõe. Fischer (2002, p. 56) problematiza essa concepção de verdades e sugere que pelo menos as colocamos em suspeitas, já que as representações que elas atribuem "habitam nosso próprio modo de pensar e existir". Por isso aceitamos determinadas verdades de maneira tão natural.

Recebido em: 20/02/2017

Aprovado em: 23/12/2017 